\title{
DETECTION OF OXIDATIVE STRESS, APOPTOSIS AND MOLECULAR LESIONS IN HUMAN OVARIAN CANCER CELLS
}

\author{
H. I. Falfushynska ${ }^{1,2,3}$ \\ 1. HORBACHEVSKY TERNOPIL STATE MEDICAL UNIVERSITY, TERNOPIL, UKRAINE \\ ${ }^{2}$ VOLODYMYR HNATIUK TERNOPIL NATIONAL PEDAGOGICAL UNIVERSITY, TERNOPIL, UKRAINE \\ ${ }^{3}$ UNIVERSITY OF NORTH CAROLINA AT CHARLOTTE, CHARLOTTE, USA
}

\begin{abstract}
Background. Ovarian cancer has the highest mortality rate of gynaecological cancers. This is partly due to the lack of effective screening markers. Indices of oxidative stress are well-recognized prognostic criteria for tumorous transformation of tissue, but their value depends on the type of tumor and the stage of its development.

Objective. The aim of this study is to clarify the relationship between antioxidant/pro-oxidant ratio and the signs of molecular lesions and apoptosis rate in blood of ovarian cancer patients and non-cancer ones.

Results. The ovarian cancer group is marked by antioxidant/prooxidant balance shifting to oxidative damage in blood as the consequence of overexpression of oxyradicals (by 300\%). Higher level of glutathione (by 366\%), lower level of metallothioneins (by 65\%) as well as higher level of lipid peroxidation (by 174\%) and protein carbonyls (by 186\%) in blood of ovarian cancer patients compared to the normal ovarian group have been observed. The signs of cytotoxicity are determined in blood of ovarian cancer patients: an increased (compared to control) level of DNA fragmentation (by 160\%), choline esterase (up to twice), higher rate of both caspase dependent and caspase independent lysosomal mediated apoptosis.

Conclusions. Cathepsin D activity both total and free, choline esterase activity, TBA-reactive substance and protein carbonyls level in blood could be used as the predictive markers of worse prognosis and the signs of human ovarian cancer.
\end{abstract}

KEY WORDS: ovarian cancer, oxidative stress, apoptosis, caspase-3, cathepsin D, choline esterase, metallothionein.

\section{Introduction}

Ovarian cancer dominates among the death causes of malignant tumours. In particular, according to the International Agency for Cancer Research, more than 165 thousand of newly diagnosed cases of ovarian cancer are registered each year over the world. Despite intensive studies, every year, more than 100000 women die from this disease worldwide. Due to minimal and non-specific early stage symptoms, ovarian cancer diagnosis is late and prognosis is usually poor [1]. Currently there are no screening programs for precancerous and malignant ovarian pathology diagnostic, with the help of which specialists could have reduced the incidence and fatalities of this disease [2].

Corresponding author: Halina Falfushynska, Department of General Chemistry, I. Horbachevsky Ternopil State Medical University, 1 Maidan Voli, Ternopil, Ukraine, 46001

Research Laboratory of Comparative Biochemistry and Molecular Biology, Volodymyr Hnatiuk Ternopil National Pedagogical University, 2 Maksym. Kryvonis Street, Ternopil, Ukraine, 46027

Tel.: +380673506531

E-mail: halynka.f@gmail.com
Therefore, exploration of new and/or low-cost early-warning molecular signatures of disease is a key goal of ovarian cancer research.

One of the most common mechanisms of diseases development and aggressiveness of pathology which is on the focus of biomedical research has been linked to overexpression of free radicals and oxidative stress initiation [3, $4,5,6,7]$. The damage that reactive oxygen species (ROS) can cause to the cell not only depends on their internal concentration but also on the equilibrium between the ROS and the endogenous antioxidants normally protect cells against oxidative stress $[4,6]$. When the antioxidant/prooxidant system becomes unbalanced, oxidative stress is generated, altering and damaging many biomolecules, including DNA, lipids and proteins, in turn, decreasing cell viability $[5,6,8,9]$. We have shown before that higher content of the products of oxidative damage of proteins, lipids, DNA fragmentation and cathepsin D activity, particularly free one are the main characteristic signs of malignant ovarian tissue [10]. However, it can be difficult 
to obtain a biopsy from ovarian tissue for routine biochemical measurements with prognostic mission of diseases development. Instead of them correspondent blood test would be highly recommended. Thus, here we aim to clarify the relationship between antioxidant/ pro-oxidant ratio and the signs of molecular lesions and apoptosis rate in blood of ovarian cancer patients and normal ovarian ones.

\section{Materials and Methods}

For this research we used the venous blood samples taken from the 15 newly diagnosed patients of reproductive age who had been operated for epithelial ovarian cancer at the Department of Gynaecology of Ternopil Regional Oncological Hospital. Cancer pathology was verified histologically. According to FIGO classification, all diagnosed patients had stage III disease. None of the operated oncologic female patients had been previously treated with platinum-based drugs (cisplatin/carboplatin/ cycloplatam) or cyclophosphamide. Venous blood of 15 females not affected by the relevant pathology were taken as controls. All experimental studies were conducted in accordance with the rules of the National Congress on Bioethics (Kyiv, 2000) and the decision of the Commission on Bioethics of the Ternopil State Medical University (№ 3, 2013).

All the procedures on bloods were carried out at $4^{\circ} \mathrm{C}$. All the reagents, except those specified below, were produced by "Synbias", 'chemically pure' grade.

The determination was conducted in the soluble fraction of blood, which had been received to determine superoxide dismutase (SOD) as a result of centrifugation of blood within $10 \mathrm{~min}$ at $6000 \mathrm{~g}(\mathrm{~S} 6)$, to determine the level of oxygen radicals - as a result of its centrifugation within $45 \mathrm{~min}$ at $12000 \mathrm{~g}$ (S12) and to determine the concentration of metallothioneins - within $45 \mathrm{~min}$ at $16000 \mathrm{~g}$ (S16).

Superoxide dismutase activity (SOD) (EC 1.15.1.1) was measured by a decrease in the rate of the reduction of Nitrotetrazolium blue in the presence of phenazine methosulfate and NADH [11]. Enzymatic activity was expressed in conventional units (CU). Enzyme activity, which was able to cause a decrease in optical density in the process of the reduction of Nitrotetrazolium blue in $50 \%$ test sample per $1 \mathrm{mg}$ of protein from the homogenate in soluble form, was taken as $1 \mathrm{CU}$.

The content of total glutathione was determined in blood after complete reduction of glutathione through the use of glutathione reductase (Sigma, USA) and with the help of Ellman's reagent [12]. The level of 5-trinitrobenzoic acid was monitored with a spectrophotometer at $412 \mathrm{~nm}$.

The determination of protein carbonyls (PC) was conducted due to their ability to form 2,4dinitrophenylhydrazones under the blood plasma incubation in the presence of $0.1 \mathrm{M} 2,4$-dinitrophenylhydrazine in $\mathrm{HCl}, 2 \mathrm{M}$. The light absorbance was registered at $370 \mathrm{~nm}$ against the control, and the content of phenylhydrazone was calculated using a molar extinction coefficient of $2.1 \times 10^{4} \mathrm{M}^{-1} \mathrm{~cm}^{-1}[13]$. Lipid peroxidation was characterized by the products of interaction between deproteinized blood after precipitation of proteins with trichloroacetic acid (with final concentration of 5\%) from blood samples and 2-thiobarbituric acid (TBA). The formation of TBA-reactive substance (TBARS) was calculated by the intensity of the absorption of a pinkcoloured complex at $532 \mathrm{~nm}$ by the molar extinction coefficient of the complex equal to $\varepsilon=1.56 \times 10^{5} \mathrm{M}^{-1} \mathrm{~cm}^{-1}[14]$.

The content of oxyradicals (OR) in S12 fraction of the blood plasma was evaluated using the non-fluorescent derivative, dihydrorhodamine, which is converted to the fluorescent dye, rhodamine-123, after a reaction with reactive oxygen species. The fluorescence signal was detected by using an $f$-max fluorescence platereader [excitation $=485 \mathrm{~nm}$, emission $=538 \mathrm{~nm}$ ] immediately and after $20 \mathrm{~min}$ and used to determine the rate of ROS formation $[10,15]$ and expressed in relative fluorescence units (RFU) per $1 \mathrm{mg}$ of protein.

The content of metallothioneins (MTs) in S16 fraction of blood was evaluated by the content of thiol groups (MT-SH) with slight modification $[8,9,10,16]$ with 5,5'-dithio-bis-2-nitrobenzoic acid (DTNB, Sigma, USA) after the chloroform-ethanol extraction of MT, and calculated assuming that $1 \mathrm{~mol}$ of MT contains the same amount of $\mathrm{SH}$-groups as 20 moles of $\mathrm{GSH}$.

Choline esterase (ChE, EC 3.1.1.7) activity was determined in blood as the acetylthiocholinecleaving ChE activity according to the colorimetric method of Ellman et al. (1961) at $25^{\circ} \mathrm{C}$ [17]. Enzyme activity was calculated using a molar extinction coefficient of $13.6 \times 10^{3} \mathrm{M}^{-1} \mathrm{~cm}^{-1}$ and standardized to the soluble protein content.

DNA damage was determined by the content of the fragmented deproteinized DNA in the total DNA by the method of alkaline pre- 
cipitation of $10 \%$ blood plasma in $50 \mathrm{mM}$ TrisEDTA buffer, pH 8.0, containing $0.5 \%$ sodium dodecyl sulfate (Sigma, USA). The supernatant contains damaged DNA molecules when the pellet contains protein and a whole DNA. DNA content in the supernatant and in the pellet was determined by the Hoescht dye in the presence of $0.4 \mathrm{M} \mathrm{NaCl}, 4 \mathrm{mM}$ of sodium cholate and $0.1 \mathrm{M}$ Tris ( $\mathrm{pH}$ 9.0) at the excitation wave (ex.)=360 nm and emission (em.)=450 nm [18]. The content of fragmented DNA was expressed as a percentage to the total DNA in the sample.

Caspase-3 activity in blood samples was measured using a colorimetric assay based on the hydrolysis of peptide acetyl-Asp-Glu-Val-Asp p-nitroanilide (Ac-DEVD-pNA) by caspase-3, resulting in a release of the $p$-nitroaniline ( $p N A)$ moiety. p-Nitroaniline was detected at $405 \mathrm{~nm}$ $\left(\varepsilon_{\mathrm{M}}=10,500 \mathrm{M}^{-1} \mathrm{~cm}^{-1}\right)[19,20]$.

The enzymatic activity of cathepsin D (EC 3.4.23.5) was determined spectrophotometrically by the formation of acid-soluble products of hemoglobin enzymatic hydrolysis $[10,21]$. The reaction mixture contained $50 \%$ blood serum in $0.25 \mathrm{M}$ of sucrose solution and, as a substrate, $1 \%$ solution of bovine hemoglobin (Sigma, USA) in $0.1 \mathrm{M}$ acetate buffer ( $\mathrm{pH}$ 5.0). The enzymatic reaction was stopped by adding $10 \%$ solution of trichloracetic acid up to a final concentration of $2 \%$. To determine the total activity of cathepsin $D$, the blood serum sample was previously treated with $1 \%$ solution of Triton X-100 (Sigma, USA) for $10 \mathrm{~min}$ at $+37^{\circ} \mathrm{C}$. The control sample was incubated at $+4^{\circ} \mathrm{C}$ for 30 min before adding $10 \%$ trichloracetic acid solution. The activity of cathepsin D was calculated by the difference in the optical density of experimental and control samples at $280 \mathrm{~nm}$ wave length and expressed as $\mathrm{nmol}$ of tyrosine/( $\min \times \mathrm{mL})$.

The results of the measurements were presented as means \pm standard deviation (SD) $\mathrm{M} \pm \mathrm{SD}$ for 15 samples of the blood of the ovarian cancer patients and the reference group. If the data was not normally distributed according to the Lilieford test, it had been transformed using the Box-Cox method. For the data that were not normally distributed even after the transformation, non-parametric tests (Kruskall-Wallis ANOVA and Mann-Whitney U-test) were performed. Differences were considered significant if the probability of Type I error was less than 0.05 . For evaluation of the antioxidative-prooxidative equilibrium we proposed the Integrated Oxidative Stress (IOS) index as the ratio of antioxidant factors (SOD, GSH and MT-SH level) and prooxidant manifestations (oxyradicals (OR), TBARS and PC) after the standardization of data $[8,9]$. The main classification criterion and relationship between biochemical parameters of the ovarian tissue samples was evaluated using the discriminant analysis and correlation analysis (Pearson's correlation coefficient $r$ under the probability of the value $p<0.05)$. All statistical calculations were performed by means of Statistica v10.0 and Excel for Windows 2010.

\section{Results and Discussion}

The results of an evaluation of antioxidant defense system parameters (Table 1) show glutathione level (by 366\%) in blood of the cancer patients is higher than in the control ones and SOD activity just commensurate in both groups. The MT-SH level (by 65\%) is lower under the ovarian cancer. At the same time, the intensity of the oxyradicals formation (by 300\%), the concentration of TBARS (by 174\%) and protein carbonyls (by 186\%) are higher in the blood of the cancer patients compared to the correspondent control ones.

The signs of cytotoxicity are determined in blood of the ovarian cancer patients: an increased (compared to the control ones) level of DNA fragmentation (by 160\%), caspase-3 activity (by $43 \%$ ) and cathepsin D activity, both of its total (by 546\%) and, particularly, free forms (by 952\%). The activity of choline esterase is twice as high as in the ovarian cancer group compared to the intact one.

The application of discriminant functional analysis (a subtype of the multivariate data analysis) to the set of studied biochemical parameters has shown that the characteristics of cathepsin D activity both total and free, choline estrase activity, TBARS and protein carbonyls level are the main criteria for differentiation of the studied groups $(F(11,18)=2353,6$, $p<0,0000)$. For an appreciation of the quantitative equilibrium between antioxidant defence and oxidative destruction, we calculated the IOS index after standardizing the data. It was lower in blood of the cancer patients (IOS=-39\%) indicating the balance shifting to oxidative damage as the consequence of tolerance limits of antioxidant defence system increased in ovarian cancer patient.

Recent studies have shown an important role for reactive oxygen species (ROS) in cancer development [5]. ROS can be produced in different endogenous sources, such as mitochondria, peroxisomes etc. [3] and are accumulated 
Table 1. Biochemical parameters in blood of ovarian cancer and normal ovarian patients, $M \pm S D, n=15$

\begin{tabular}{|c|c|c|}
\hline \multirow{2}{*}{ Parameter } & \multicolumn{2}{|c|}{ Groups } \\
\hline & Normal ovarian & Ovarian cancer \\
\hline MT-SH content, $\mu \mathrm{g} \cdot \mathrm{mL}^{-1}$ of blood & $16.2 \pm 1.9$ & $5.6 \pm 0.7 *$ \\
\hline Total glutathione content, $\mathrm{mmol}^{-\mathrm{L}^{-1}}$ of blood & $0.9 \pm 0.1$ & $4.2 \pm 0.8^{*}$ \\
\hline SOD activity, CU. $\mathrm{mg}^{-1}$ of protein & $1.8 \pm 0.2$ & $1.6 \pm 0.2$ \\
\hline TBARS content, $\mathrm{nmol} \cdot \mathrm{mL}^{-1}$ of blood & $19.4 \pm 2.5$ & $53.1 \pm 6.2 *$ \\
\hline Protein carbonyls level, $\mathrm{nmol} \cdot \mathrm{mg}^{-1}$ of plasma proteins & $0.7 \pm 0.2$ & $2.0 \pm 0.3 *$ \\
\hline Cholin esterase, $\mathrm{nmol} \cdot \mathrm{min}^{-1} \cdot \mathrm{mg}^{-1}$ proteins & $0.38 \pm 0.04$ & $1.25 \pm 0.18 *$ \\
\hline Oxygen radicals content, RFU. $\mathrm{mg}^{-1}$ of protein & $0.94 \pm 0.08$ & $3.76 \pm 0.42 *$ \\
\hline Caspase- 3, pmol. $\cdot \mathrm{min}^{-1} \cdot \mathrm{mg}^{-1}$ proteins & $7.7 \pm 0.8$ & $11.0 \pm 1.3^{*}$ \\
\hline Total activity of cathepsin $\mathrm{D}, \mathrm{nmol} \cdot \mathrm{min}^{-1} \cdot \mathrm{mL}^{-1}$ of blood serum & $2.2 \pm 0.3$ & $14.2 \pm 1.2 *$ \\
\hline Free cathepsin D activity, $\mathrm{nmol} \cdot \mathrm{min}^{-1} \mathrm{~mL}^{-1}$ of blood serum & $0.96 \pm 0.07$ & $10.10 \pm 0.89 *$ \\
\hline Content of fragmented DNA in total DNA, \% & $3.0 \pm 0.4$ & $7.8 \pm 0.5^{*}$ \\
\hline
\end{tabular}

Note. * - differences compared to the blood samples of the reference group, $p<0.05$.

under an imbalance between their production and elimination by protective mechanisms, referred to as antioxidants. ROS are overproduced a long time, then, may cause DNA, protein, and/or lipid damage [7]. In our case the ovary cancer is also said to be under oxidative stress (IOS less than zero) associates with the most prominent upraise of oxidative lesions (triple of them, TBARS, protein carbonyls and oxyradicals). We speculate that oxidative stress causes injury to cells, among them initiation of DNA strand breaks (DNAsb $=1.65-0.02 \times$ TBARS+ $1.93 \times \mathrm{PC}^{*}+0.65 \times \mathrm{OR} *, \mathrm{R}^{2}=0.98, \mathrm{~F}(6,23)=212,69$, $\mathrm{p}<0.001 ; *$ - parameter makes a presumable contribution to the mathematical model) and liberation of cathepsin $D$ from lysosomes (Cathepsin D $($ free $)=-3.69+0.19 \times$ TBARS $^{*}+0.78 \times$ $\left.P C+0.48 \times O R, R^{2}=0.96, F(6,23)=210,05, p<0.001\right)$. It is established that cathepsins, released from lysosomes in course of oxidative injury of membranes [22], cleave Bid, which activates the mitochondrial apoptosis pathway [23]. Thus, human ovary cancer progression is linked to oxidative stress directly by increasing DNA fragmentation and caspase-independent lysosomal-mediated apoptosis pathway.

A failure to undergo apoptosis is considered to be a key event in cancer formation and progression [24]. Using the key mediators of mitochondrial events of apoptosis, caspase 3, we have shown that ovarian cancer exhibits higher rates of apoptosis than either samples of the control group. Data about caspase 3 role in cancer progress and patients survival are controversial; and it has been demonstrated that expression of caspase-3 does not correlate with the extent of apoptosis in primary carcinomas [25]. Some investigators have also reported increased rates of apoptosis in diffe- rent types of cancer, breast carcinomas among them. But, on the other hand, it has been shown that loss of caspase-3 expression may decrease breast cancer cells resistant to chemotherapy and radiation therapy [26].

Many studies have found that the expression level of AChE and/or BChE increases during apoptosis in various cell types and alter human breast, lung cancer, leukemia etc progress [27]. Many tumours, including ovarian carcinoma, express ChEs, indicating that the enzymes may be functionally important in neoplastic cell transformation, and can be considered a marker of early differentiation [28]. In breast cancer AChE activity is as in twice as high as in normal breast. The difference in lectin reactivity between erythrocyte and breast AChE, the lack of AChE in blood plasma suggest that breast epithelial cells produce AChE for membrane attachment [27]. It has also been demonstrated that AChE can hydrolyse lipid peroxides, which may support the possibility that a reduction in enzyme activity augments oxidative stress and cellular damage of bronchopulmonary epithelial cells [29]. We have also shown in our study the concordant changes of choline esterase and caspase-3 activity $(r=0.83, p<0.001)$ strongly suggest that $\mathrm{ChE}$ is an important component in the common pathway leading to apoptosis in human ovarian cancer and future studies of such mechanisms would be of great interest.

Several in vitro studies have demonstrated the importance of MTs expression for cancer cell growth and survival. On the one hand overexpression of MTs has been reported for different type of cancers and MT levels have been correlated with increasing tumour grade in different ones [30, 31]. But, on the other hand, the downregulation of MT protein production 
resulted in dramatic growth inhibition of several human cancer cell lines. Similarly, when MT expression was abolished in human PC-3 prostate and SKOV-3 ovarian cancer cell lines using a specific ribozyme, there is a marked increase in spontaneous apoptosis [32]. We have also found that lower level of MTs in ovarian cancer group potentially caused the caspasedependent apoptosis pathway activation $(r=-0.86, p<0.001)$. We speculate that apoptotic activation is dependent on MTs levels via zinc, because it is a potent inhibitor of caspase-3 [33]. It is recognised that depletion of zinc by chelation has been shown to promote apoptosis in vitro [34]. Therefore, zinc bound to MTs may play a crucial role in the control of apoptosis. Apoptosis rate would be as higher as less zinc is liberated in cells containing less MTs. Our present findings are in good correlation with our previous work that demonstrated decreased zinc concentration in the samples of ovarian cancer tissue compared with normal ovarian [10].

\section{Conclusions}

Using the multi-marker analysis of stressrelated processes in the ovarian cancer we determined a number of blood characteristics, which compound the pathological changes in the malignant tissue; the imbalance between antioxidants and oxidative lesions, appearance of DNA strand breaks and activation of both caspase dependent and caspase independent lysosomal mediated apoptosis pathway are among them. Cathepsin D activity, both total and free, choline esterase activity, TBARS and protein carbonyls level can be used as the predictive markers of worse prognosis and the signs of human ovarian cancer. Metallothioneins down-regulation and choline esterase activation in blood are ultimately resulting in intrinsic apoptosis pathway in ovarian cancer. The further studies are needed to elucidate the mechanism by which choline esterase regulates caspase-3 dependent apoptosis in human ovarian cancer.

\section{Acknowledgements}

The research was supported by the WestUkrainian Biomedical Center, the Ministry of Education and Science of Ukraine (State Budget Topic № 125B) and Fulbright Scholar grant.

\section{References}

1. Howlader N, Noone AM, Krapcho M, Garshell J, Neyman N, Altekruse SF et al. SEER Cancer Statistics Review, 1975-2010, National Cancer Institute. Bethesda, MD, http://seer.cancer.gov/csr/1975_2010/, based on November 2012 SEER data submission, posted to the SEER web site (accessed, April 2013). Controlled Trial. JAMA 2011; 305: 2295-2303.

2. Klaunig JE, Kamendulis LM, Hocevar BA. Oxidative stress and oxidative damage in carcinogenesis. Toxicol Pathol 2010; 38: 96-109.

3. Mahalingaiah PKS, Singh KP. Chronic oxidative stress increases growth and tumorigenic potential of MCF-7 breast cancer cells. PLOS ONE 2014; 9: e93799.

4. Reuter S, Gupta SC, Chaturvedi MM, Aggarwal BB. Oxidative stress, inflammation, and cancer: How are they linked? Free Radic Biol Med 2010; 49: 1603-1616.

5. Valko M, Rhodes CJ, Moncol J, Izakovic M, Mazur M. Free radicals, metals and antioxidants in oxidative stress-induced cancer. Chem Biol Interact 2006; 160: 1-40.

6. Visconti R, Grieco D. New insights on oxidative stress in cancer. Curr Opin Drug Discov Devel 2009; 12: $240-245$.
7. Falfushynska H, Gnatyshyna L, Shulgai A, Shidlovsky V, Stoliar O. Oxidative stress in human thyroid gland in cases of iodine deficiency nodular goitre: from harmlessness to hazard depending on copper and iodine subcellular distribution. Int J Med Medical Res 2015; 1: 5-11.

8. Falfushynska HI, Gnatyshyna LL, Osadchuk OY, Shidlovsky VO, Stoliar OB. Trace elements storage and metallothioneins function in cases if human thyroid gland transformation. Ukr Biochem J 2014; 86: 107-113.

9. Falfushynska HI, Gnatyshyna LL, Deneha HV, Osadchuk OY, Stoliar OB. Manifestations of oxidative stress and molecular damages in ovarian cancer tissue. Ukr Biochem J 2015; 87: 93-102.

10. Beauchamp C, Fridovich I. Superoxide dismutase: improved assay and an assay applicable to acrylamide gels. Anal Biochem 1971; 44: 276-287.

11. Anderson ME. Determination of glutathione and glutathione disulfide in biological samples. Meth Enzymol 1985; 113: 548-555.

12. Lushchak VI, Bagnyukova TV, Lushchak OV. Indices of oxidative stress. 1. TBA-reactive substances and carbonylproteins. Ukr Biochem J 2004; 76: 136-141. 
13. Ohkawa H, Ohishi N, Tagi K. Assay for lipid peroxides in animal tissues by thiobarbituric acid reaction. Anal Biochem 1979; 95: 351-358.

14. Viarengo A, Burlando B, Cavaletto M, Marchi $B$, Ponzano E, Blasco J. Role of metallothionein against oxidative stress in the mussel Mytilus galloprovincialis. Am J Physiol 1999; 277: 1612-1619.

15. Viarengo A, Ponzano E, Dondero F, Fabbri R. A simple spectrophotometric method for metallothionein evaluation in marine organisms: an application to Mediterranean and Antarctic molluscs. Mar Environ Res 1997; 44: 69-84.

16. Ellman GL, Courtney KD, Andres VJ, Featherstone RM. A new and rapid colorimetric determination of acetylcholinesterase activity. Biochem Pharmacol 1961; 7: 88-95.

17. Olive PL. DNA precipitation assay: a rapid and simple method for detecting DNA damage in mammalian cells. Environ Mol Mutagen 1988; 11: 487495.

18. Bonomini M, Dottori S, Amoroso A, Arduini A, Sirolli V. Increased platelet phosphatidylserine exposure and caspase activation in chronic uremia. J Thromb Haemost 2004; 2: 1275-1281.

19. Falfushynska H, Gnatyshyna L, Fedoruk O, Mitina N, Zaichenko A, Stoliar O, Stoika R. Hepatic metallothioneins in molecular responses to cobalt, zinc, and their nanoscale polymeric composites in frog Rana ridibunda. Comp Biochem Physiol 2015; 172-173: 45-56.

20. Dingle JT, Barrett AJ, Weston PD. Cathepsin D. Characteristics of immunoinhibition and the confirmation of a role in cartilage breakdown. Biochem J 1971; 123: 1-13.

21. Yu C, Huang $X, X u Y$, Li H, Su J, Zhong J et al. Lysosome dysfunction enhances oxidative stressinduced apoptosis through ubiquitinated protein accumulation in Hela cells. Anat Rec (Hoboken) 2013; 296: 31-39.

22. Stoka V, Turk B, Schendel SL, Kim TH, Cirman T, Snipas SJ et al. Lysosomal protease pathways to apoptosis. J Biol Chem 2001; 276: 3149-3157.

23. Herr I, Debatin K-M. Cellular stress response and apoptosis in cancer therapy. Blood 2001; 98 : 9.
24. Faraglia B, Bonsignore $A$, Scaldaferri $F$, Boninsegna A, Cittadini A, Mancuso C, Sgambato A. Caspase- 3 inhibits the growth of breast cancer cells independent of protease activity. J Cell Physiol 2005; 202: 478-482.

25. Devarajan E, Sahin AA, ChenJS, Krishnamurthy RR, Aggarwal N, Brun AM et al. Down-regulation of caspase 3 in breast cancer: a possible mechanism for chemoresistance. Oncogene 2002; 21: 88438851.

26. Ruiz-Espejo F, Cabezas-Herrera J, Illana J, Campoy FJ, Vidal CJ. Cholinesterase activity and acetylcholinesterase glycosylation are altered inhuman breast cancer. Breast Cancer Res Treat 2002; 72: 11-22.

27. Zakut H, Ehrlich G, Ayalon A, Prody CA, Malinger G, Seidman S et al. Acetylcholinesterase and butyrylcholinesterase genes coamplify in primary ovarian carcinomas. J Clin Invest 1990; 86: 900-908.

28. Fuhrman B, Partoush A, Aviram M. Acetylcholine esterase protects LDL against oxidation. Biochem Biophys Res Commun 2004; 322:974-978.

29. Bay B-H, Jin R, Huang J, Tan P-H. Metallothionein as a prognostic biomarker in breast cancer. Exp Biol Med 2006; 231: 1516-1521.

30. Takeda A, Hisada H, Okada S, Mata JE, Ebadi $\mathrm{M}$, Iversen PL. Tumor cell growth is inhibited by suppressing metallothionein-I synthesis. Cancer Lett 1997; 116: 145-149.

31. Tekur S, Ho S-M. Ribozyme-mediated downregulation of human metallothionein II(a) induces apoptosis in human prostate and ovarian cancer cell lines. Mol Carcinog 2002; 33: 44-55.

32. Aiuchi T, Mihara S, Nakaya M, Masuda $Y$, Nakajo S, Nakaya K. Zinc ions prevent processing of caspase-3 during apoptosis induced by geranylgeraniol in HL-60 cells. J Biochem 1998; 124: 300-303.

33. Chimienti F, Seve M, Richard S, Mathieu J, Favier A. Role of cellular zinc in programmed cell death: temporal relationship between zinc depletion, activation of caspases, and cleavage of Sp family transcription factors. Biochem Pharmacol 2001; 62: 51-62. 